\title{
CAN THE BLASTING EXCAVATION ENGINEERING SCIENCES PROVIDE INSIGHT INTO THE PROCESSES OF KIMBERLITE EMPLACEMENT AND ERUPTION?
}

\author{
Rice, A. ${ }^{1}$
}

1. Depts of Physics and Geology, Rhodes University, Grahamstown, 6140, South Africa

Well-known engineering and applied physics relationships pertaining to explosive excavation (to estimate, for instance, dispersion and grading of ejecta, cratering configurations, etc) give indication they may be useful in describing kimberlite emplacement and eruption. This engineering technology has been established for some time (e.g., Hino, 1959). All underground "chimneys" (a vertically oriented cylinder of rubble in the earth) formed by blasting display a preference for the $82^{\circ}$ angle from the horizontal to diatreme wall that characterizes kimberlite pipes. If it is assumed that the kimberlitic forming material "parked" in the upper crust and then exploded there to breach the surface, then one may appeal to a variety of relationships to estimate burden (or DOB - depth of burden) overlying the explosive charge and the charge dimensions themselves. Estimates may also be made of crater radius, volume, or depth. Conditions conducive to full cratering or complete containment (little surface expression of blast at depth) or whether the material will be fully or partially broken out can also be inferred. All these relationships show consistency amongst each other and with kimberlite field observations. If kimberlitic material does "park" initially a kilometre or so beneath the earth's surface before exploding, then various means are available to estimate blast energy and pressures: e.g., possibly reaching approximately $10^{18}$ joules and 100 kbars, respectively.

Acknowledgements: the inputs of Drs J. Gurney, Dept. Of Geological Sciences, University of Cape Town; E.W.M. Skinner, Dept. Of Geology, Rhodes University and J. Brown, Camborne School of Mines, U.K., are deeply appreciated.

\section{References}

Hino, K., 1959, Theory and Practice of Blasting, Nippon Kayaku Co., Ltd, Japam, 197 pgs. 